\title{
Game-based language learning in the context of distance education
}

\author{
Natalia Nikolaevna Levina*, Tatyana Philippovna Petrenko, Gurgen Eduardovich \\ Airapetov, and Marina Aleksandrovna Ryashchenko \\ Pyatigorsk State University, Department of French Philology and Intercultural Communication, \\ Pyatigorsk, Russia
}

\begin{abstract}
The abrupt transition of the educational institutions to distance learning because of objective reasons related to the Covid-19 pandemic and the social isolation required the teachers to review the existing approaches to the classes organization and make appropriate changes. Rethinking traditional methods with game-based technologies expect not to "lose" contact with the audience and maintain its learning motivation. This study aims to generalize the experience of game-based technologies incorporation in university French classes at different levels to preserve and enhance the students learning motivation in the context of distance education. The scientific problem considered in the article fits into the problems of research aimed at studying the effective teaching methods and technologies that contribute to forming the students' motivation. To achieve the research goal, the inductive-deductive method is used, as well as the methods of situational analysis. The analysis of existing approaches to the motivation phenomenon allowed the authors to define its importance in teaching foreign languages and to determine the role of the game-based methods in learning motivation enhancement. The result of the study is a demonstration of applied game-based technologies and their positive impact on learning motivation during distance education.
\end{abstract}

Keywords: language learning, game-based technologies, distance education, motivation

\section{Introduction}

The transition to distance education, dictated by the current epidemiological situation in March 2020, posed a number of questions that require urgent decisions for both Russian and foreign higher education systems.

The papers analyzing the sociological studies data and evaluating the processes associated with the transition to distance education reveal that the domestic and foreign higher education systems have coped quite effectively with the new conditions [1-3]. Researchers are considering the possibility of preserving this format in blended learning,

\footnotetext{
*Corresponding author: taanari@yandex.ru
} 
creating online courses that would contribute to the implementation of an individual educational learning trajectory $[2,4,5]$.

Despite the general positive assessment of the distance education possibilities, the authors of scientific publications and analytical reviews based on the opinion polls data note a number of difficulties that all participants in the educational process had to face. We can talk about the universal nature of the identified problems, since they do not have "nationality, age and social differences". These difficulties are conditionally divided into two groups: technical and personal, psychological.

Technical problems include insufficiently high Internet connection speed, not always good communication quality and lack of equipment necessary for participation in online classes $[1,3]$. The technical difficulties that both students and teachers had to face were compounded for the latter by the relevant learning methods and strategies selection to be most effective for each particular discipline [4].

Psychological problems that significantly complicated the transition to the digital format of educational process were the lack of self-organization skills, the need for external control and an insufficient level of students' personal motivation $[1,4,5]$.

Thus, the cornerstone of distance education has become student's motivation as the basis of independent cognitive activity, stimulating the student not only to acquire certain knowledge, but what seems much more important, to work independently with information. Teachers needed to mobilize all their professional skills to combine professional activity with self-education and simultaneously stimulate students' learning motivation, being in a constant feedback mode. McCombs and Pope mentioned that teachers became the "motivation resource" in the situation of transition to digital learning [6].

Nowadays, numerous approaches to motivation, its nature and structure are known. We accept the Fenouillet's definition as relevant: "motivation is a hypothetical variable individual internal force that can have multiple internal and/or external determinants, and which allows explaining the starting point, direction, constancy and intensity of behavior or action" [7].

One of the means to enhance language-learning motivation is the use of active methods including game-based technologies. Learning through entertainment is an important principle in the socio-cultural and professional competencies formation.

According to Silva, one of the main features of game-based technologies is their capacity to "overcome resistance, encourage activity and master the material, regardless of abilities" [8]. Functionally, game-based technologies contribute to socialization, interaction, the implication of communication strategies, the development of cognitive and language skills, underlined Silva. The main advantages of game-based methods in language teaching include their ability to motivate students and promote the manifestation of personal initiative and responsibility for their education. According to Vauthier [9], the game has many advantages, including motivating students, facilitating their concentration and using memory. The game creates a positive pedagogical climate in which the fault is eliminated, and the attention focus moves from the language content to the playful task that needs to be completed. So game allows students to be motivated and thus contribute to their learning success.

\section{Methods}

The general scientific methodology of this study was the postulates of the concept of learning motivation, set out in the works of Gardner, Dörney, Fenouillet and the theory of language game, presented in the works of Sannikov, Heising, Beregovskaya. The 
methodological and theoretical basis of the analysis was made up of the research papers devoted to the use of game technologies in distance learning (Bahari [10], Zhang [11], Liu).

To achieve the research goal, the inductive-deductive method is used, as well as the methods of situational analysis.

\section{$3 \quad$ Results}

The integration of game-based technologies into foreign language teaching is of great importance both for the acquisition of new skills and abilities by students, and for the development of the motivational and need sphere, since it allows the teacher to "manage" the motivation of students and direct it. In the distance education context, the opportunity to use all their verbal and communicative resources together and creatively through the game is of particular value for students [12]. It is this type of activity that allows to work in a team and maintain personal contact despite the fact that the participants are not together in the audience.

The variety of game-based technologies is quite wide. We begin with the use of game elements to perfect the acquired knowledge, skills and abilities at the initial level of language learning. Then, at intermediate and advanced levels we use role-playing games as an autonomous unit of the learning process, to activate mental activity, to form creative thinking and improve professional competencies. All these technologies were applied in online learning during the pandemic.

The experience of distance education has shown that for beginners it is important to introduce game elements through the use of various online resources, such as Duolingo, LearningApps, Tandem. Teachers have the opportunity to present educational content in a playful way. Using these platforms both during remote classes and for organizing independent work allows improving the acquired language skills and speech abilities. A valuable quality of such educational resources is the ability to create a wide range of tasks aimed at the development of all types of speech activity, as well as the authenticity and relevance of the materials underlying each exercise. All of the above contributes to the formation of interest and the need to learn a language, that is, creates favorable conditions to develop the internal motivation.

The advanced learning levels, focused on improving linguistic and intercultural competencies with the simultaneous formation of professional skills, make it possible to use educational role-playing games. For example, in order to form professional competence that allows overcoming the influence of stereotypes and adapting to changing conditions in contact with representatives of different cultures, in French classes we tried role-playing games "In the captivity of stereotypes" and "Gastronomic games" in the format of online talk shows. Such a format of classes makes possible to realize "intercultural communication" taking into account national behavior peculiarities and communicative styles in various situations. We pointed out the active students' involvement to prepare and implement the role-playing games, while using game-based methods at the advanced learning level. As well as to get each participant active and responsible for the result of the entire project. In the distance learning, the opportunity to organize the interaction of the teacher and students at all stages of the role-playing game in real time made it possible to overcome social isolation negative emotions and maintain their educational motivation.

\section{Discussion}


Our experience in using game-based technologies in distance learning confirmed the hypothesis that the game gives students the opportunity and need to show their cognitive and professional competencies, thereby stimulating internal motivation for self-expression.

Besides it correlates with the results presented in the papers of domestic and foreign researchers. Thus, the study by Luchinina and Batalova [13] provides experimental data confirming that the use of game-based methods in foreign language classes is an effective means of teaching and developing intercultural communication skills, which also contributes to the creation of a favorable psycho-emotional background in the learning process. The study of Kushnyr and Prikhodchenko [14] presents the results of an experiment revealed that the use of game-based technologies in the distance language learning stimulates the students' cognitive and communicative skills, provides a high level of material assimilation, moreover, it contributes to learning motivation increase. Similar conclusions were reached by Liu, Shaikh and Gazizova [15], focusing on the effectiveness of game-based learning for the development of psychological and behavioral skills indispensable in modern technological and social conditions.

\section{Conclusion}

Our experience of using game-based methods and technologies at different French learning levels proves that they are an excellent tool for interaction, since they enable students to implement both general and professional communicative situations, independently finding and using the appropriate, means "live" language and speaking tools, and not limited to simple reproduction of educational material. Thus, the game appears as a full-fledged learning tool. Its advantages are diverse. First, these methods help to develop the students' personal qualities, such as self-confidence, ability to interact, socialization. Besides, the game-based learning allows one to work on all language activities and stimulate motivation based on autonomy and competence.

The global digitalization and learning hybridization inherited by the education system opens up broad prospects for game-based methods and technologies as the main lines in language learning, allowing interaction outside the institutional framework in different contexts and along different trajectories.

\section{References}

1. I.A. Aleshkovskiy, et al., Higher Edu Rus, 29(10), 86-100 (2020). https://doi.org/10.31992/0869-3617-2020-29-10-86-100

2. L.K. Gordeeva, et al., Azim Sci Res: Pedag Psy, 10(1(34)), 196-198 (2021). https://doi.org/10.26140/anip-2021-1001-0049

3. E. Croze, Distances et Médiations des Savoirs, 33 (2021). https://doi.org/10.4000/dms.6134

4. V.A. Zernov, et al., Sci Works Free Econ Soc Rus, 223(3), 304-322 (2020). https://doi.org/10.38197/2072-2060-2020-223-3-304-322

5. S. Androwkha, Médiations Et Médiatisations, 3, 59-67 (2020). https://doi.org/10.52358/mm.vi3.116

6. B. McCombs, J. Pope, Motiver ses élèves : donner le goût d'apprendre (De Boeck Supérieur, Paris, 2000)

7. F. Fenouillet, Les théories de la motivation (Hachette, 2012) 
8. H. Silva, Le jeu en classe de langue (CLE International, Paris, 2008)

9. E. Vauthier, Cahiers Pédag, Dossier, 448 (2006)

10. A. Bahari, et al., SpringerPlus, 5, 1305 (2016). https://doi.org/10.1186/s40064-016-2971-1

11. R. Zhang, G. Cheng, X. Chen, PLoS ONE, 15(12), (2020). https://doi.org/10.1371/journal.pone.0243827

12. J.-P. Cuq, I. Gruca, Cours de didactique du français langue étrangère et seconde (PUG, Grenoble, 2002)

13. E.N. Luchinina, M.G. Batalova, Pedag. Theory Prac, 5(4), 382-386 (2020)

14. M.A. Kushnyr, P.I. Prikhodchenko, Pedag. Theory Prac, 5(4), 469-473 (2020)

15. Z.Y. Liu, Z. Shaikh, F. Gazizova, Edu. Int J Emerg Tech Learn, 15(14), 53-64 (2020). https://doi.org/10.3991/ijet.v15i14.14675 